ICUsteps, Warwick, UK

2 Wellcome-Wolfson Institute for Experimental Medicine, Queen's University Belfast, Belfast, UK

3 Kadoorie Centre for Critical Care Research, University of Oxford, John Radcliffe Hospital, Oxford, UK

Correspondence to: C White catherine.white@icusteps.org Cite this as: $B M J 2021 ; 373: n 910$ http://dx.doi.org/10.1136/bmj.n910 Published: 15 April 2021

\title{
Rehabilitation after critical illness
}

\section{Essential for all intensive care patients, not just people recovering from covid-19 Catherine White, ${ }^{1}$ Bronwen Connolly, ${ }^{2}$ Matthew James Rowland ${ }^{3}$}

Covid-19 has raised public awareness about critical illness, but there has been less focus on establishing the services and infrastructure required to support patients in their recovery after hospital discharge. The burden experienced by patients who survive critical illness is well documented. ${ }^{12}$ The symptoms are collectively known as post-intensive care syndrome and can include long term physical impairments such as muscle weakness, weight loss, breathlessness ${ }^{3}$; cognitive impairment such as problems with memory, attention, and executive function ${ }^{4}$; and psychological symptoms such as depression ${ }^{5}$ or anxiety. ${ }^{6}$ Those recovering from covid 19 are also more likely have additional respiratory sequelae..$^{-9}$ Furthermore, deficits in quality of life can persist for up to 12 years after critical illness ${ }^{10}$ with many people unable to return to work. ${ }^{11}$ Families of patients can also be deeply affected by their experience. $^{12}$

In 2009 guidance from the National Institute for Health and Care Excellence (NICE) ${ }^{13}$ outlined the requirements for optimum rehabilitation services after critical illness. These included structured rehabilitation programmes, continuity of care, information provision, and follow-up clinics. However, these guidelines failed to translate into improved support for all patients, with national survey data from 2014 indicating that less than a third of intensive care units offered follow-up when recommended, and even fewer hospitals offered post-hospital discharge rehabilitation programmes. ${ }^{14}$ In the absence of robust and widespread community based recovery and rehabilitation services, patients and families must cope alone or rely on their primary care professionals, who may have limited experience supporting patients after critical illness.

There is much to admire in how the patient voice has highlighted the longer term effects of covid-19 and made the case for community rehabilitation. NHS England has invested heavily, establishing 60 multidisciplinary clinics nationwide to support patients recovering from covid-19. ${ }^{15}$ However, a recent study identified no discernible difference between the rehabilitation needs of patients with covid-19 and those admitted to intensive care with other critical illnesses. ${ }^{16}$ The authors highlight this inequality of access for patients with and without covid-19 and suggest that heightened awareness of healthcare staff or the wider public may be contributing to better rehabilitation services for patients with covid-19. ${ }^{16}$

Providing consistent rehabilitation services is challenging. Lack of high quality evidence about the most effective approach is a problem for commissioners and service managers, for example. ${ }^{141718}$ New services need adequate funding and staffing with experienced clinicians from multiple specialties.Robust processes and tools are required to screen all patients for post-intensive care syndrome. Enhanced links between hospitals and primary care are essential to facilitate the transition to community settings and to deliver seamless continuity of care that includes ongoing rehabilitation. Engagement from NHS management and other stakeholders such as commissioners, clinicians, and integrated care systems is key to successful delivery.

\section{Better care}

Lack of adequate rehabilitation has serious consequences for individuals and risks increasing costs to the NHS, particularly from unplanned readmissions to intensive care units. ${ }^{19}$ Consistent with the 2009 NICE guidance, ${ }^{13}$ rehabilitation should be provided to all patients after critical illness, not just those with covid-19. Follow-up is essential to identify enduring impairments and facilitate referral to specialist rehabilitation services when required.

Services should include healthcare professionals who recognise the diversity of physical and mental health problems that can follow a critical illness and be supplemented by high quality, comprehensive, and individually tailored information for patients and relatives to guide recovery. ${ }^{20}$ Research to determine the most clinically and cost effective rehabilitation strategies should be a priority, with collaboration between patients, funders, and researchers to identify and address evidence gaps.

Many guidelines on rehabilitation for patients with covid-19 have been published in the past year, but just two have considered broader services for people recovering from critical illness following discharge from intensive care. Firstly, the National Post-ICU Rehabilitation Collaborative developed a framework for assessing the needs of patients stepping down from intensive care..$^{21}$ Embedded in the framework is the "post-ICU presentation screen," a validated tool that identifies individual rehabilitation requirements and can be adapted as patients' needs change. ${ }^{1622}$ Secondly, the Faculty of Intensive Care Medicine published provisional guidance from its "life after critical illness" programme, recommending follow-up, including assessment of rehabilitation needs. ${ }^{23}$ Both provide clinicians with some direction for clinical practice, but their effect must be maximised by provision of funding and further work on UK-wide implementation, with meaningful patient input to inform and develop models based on user experience.

Management of critically ill patients in intensive care units requires highly skilled and expert 
multidisciplinary teams to ensure best outcomes. The same approach is needed to support the rehabilitation of all patients after discharge from intensive care and hospital, with consistent pathways of care across the country to ensure all patients achieve their best possible recovery.

Competing interests: The BM/ has judged that there are no disqualifying financial ties to commercial companies. The authors declare no other interests. The BMJ policy on financial interests is here: https://www.bmj.com/sites/default/files/attachments/resources/2016/03/16-current-bmj-educationcoi-form.pdf.

Patient and public involvement: CW is a former critical care patient.

Provenance and peer review: Not commissioned; externally peer reviewed.

1 Inoue S, Hatakeyama J, Kondo Y, etal. Post-intensive care syndrome: its pathophysiology, prevention, and future directions. Acute Med Surg 2019;6:233-46.

doi: 10.1002/ams2.415 pmid: 31304024

2 Needham DM, Davidson J, Cohen H, etal. Improving long-term outcomes after discharge from intensive care unit: report from a stakeholders' conference. Crit Care Med 2012;40:502-9. doi: 10.1097/CCM.0b013e318232da75 pmid: 21946660

3 Ohtake PJ, Lee AC, Scott JC, etal. Physical impairments associated with post-intensive care syndrome: systematic review based on the World Health Organization's international classification of functioning, disability and health framework. Phys Ther 2018;98:631-45. doi: 10.1093/ptj/pzy059 pmid: 29961847

4 Pandharipande PP, Girard TD, Jackson JC, etalBRAIN-ICU Study Investigators. Long-term cognitive impairment after critical illness. N Engl J Med 2013;369:1306-16. doi: 10.1056/NEJMoa1301372 pmid: 24088092

5 Rabiee A, Nikayin S, Hashem MD, etal. Depressive symptoms after critical illness: a systematic review and meta-analysis. Crit Care Med 2016;44:1744-53. doi: 10.1097/CCM.0000000000001811 pmid: 27153046

6 Nikayin S, Rabiee A, Hashem MD, etal. Anxiety symptoms in survivors of critical illness: a systematic review and meta-analysis. Gen Hosp Psychiatry 2016;43:23-9. doi: 10.1016/j.genhosppsych.2016.08.005 pmid: 27796253

7 Mo X, Jian W, Su Z, etal. Abnormal pulmonary function in COVID-19 patients at time of hospital discharge. Eur Respir /2020;55:2001217. doi: 10.1183/13993003.01217-2020 pmid: 32381497

8 Torres-Castro R, Vasconcello-Castillo L, Alsina-Restoy X, etal. Respiratory function in patients post-infection by COVID-19: a systematic review and meta-analysis. Pulmonology 2020:S2531-0437(20)30245-2. doi: 10.1016/j.pulmoe.2020.10.013. pmid: 33262076

9 You J, Zhang L, Ni-Jia-Ti MY, etal. Anormal pulmonary function and residual CT abnormalities in rehabilitating COVID-19 patients after discharge. J Infect 2020;81:e150-2. doi: 10.1016/j.jinf.2020.06.003 pmid: 32512021

10 Flaatten H, Kvåle R. Survival and quality of life 12 years after ICU. A comparison with the general Norwegian population. Intensive Care Med 2001;27:1005-11. doi: 10.1007/s001340100960 pmid: 11497132

11 Kamdar BB, Suri R, Suchyta MR, etal. Return to work after critical illness: a systematic review and meta-analysis. Thorax2020;75:17-27. doi: 10.1136/thoraxjnl-2019-213803 pmid: 31704795

12 Cameron II, Chu LM, Matte A, etalRECOVER Program Investigators (Phase 1: towards RECOVER)Canadian Critical Care Trials Group. One-year outcomes in caregivers of critically ill patients. N Engl J Med 2016;374:1831-41. doi: 10.1056/NEJMoa1511160 pmid: 27168433

13 NICE. Rehabilitation after critical illness. NICE clinical guideline 83. 2009. https://www.nice.org.uk/guidance/cg83

14 Connolly B, Douiri A, Steier J, Moxham J, Denehy L, Hart N. A UK survey of rehabilitation following critical illness: implementation of NICE Clinical Guidance 83 (CG83) following hospital discharge. BMJ Open 2014;4:e004963. doi: 10.1136/bmjopen-2014-004963. pmid: 24833691

15 NHS England. NHS launches 40 'long COVID’ clinics to tackle persistent symptoms. 15 Nov 2020. https://www.england.nhs.uk/2020/11/nhs-launches-40-long-covid-clinics-to-tackle-persistentsymptoms/

16 Puthucheary Z, Brown C, Corner E, etal. The post-ICU presentation screen (PICUPS) and rehabilitation prescription (RP) for intensive care survivors part II: clinical engagement and future directions for the national Post-Intensive Care Rehabilitation Collaborative. J Intensive Care Soc 2021;1751143720988708. doi: 10.1177/1751143720988708.

17 Connolly B, Salisbury L, O'Neill B, etalERACIP Group. Exercise rehabilitation following intensive care unit discharge for recovery from critical illness. Cochrane Database Syst Rev 2015;(6):CD008632. doi: 10.1002/14651858.CD008632.pub2 pmid: 26098746

18 Schofield-Robinson OJ, Lewis SR, Smith AF, McPeake J, Alderson P. Follow-up services for improving long-term outcomes in intensive care unit (ICU) survivors. Cochrane Database Syst Rev2018;11:CD012701. doi: 10.1002/14651858.CD012701.pub2 pmid: 30388297

19 Lone NI, Lee R, Salisbury L, etal. Predicting risk of unplanned hospital readmission in survivors of critical illness: a population-level cohort study. Thorax 2019;74:1046-54 doi: 10.1136/thoraxjnl-2017-210822 pmid: 29622692

20 NICE. Rehabilitation after critical illness in adults. Quality standard QS158. 2017. https://www.nice.org.uk/guidance/qs158/chapter/About-this-quality-standard
21 National Post Intensive Care Rehabilitation Collaborative. Responding to covid-19 and beyond. Framework for assessing early rehabilitation needs following treatment in intensive care, Version 1. 2020. https://members.ics.ac.uk/ICS/ICS/GuidelinesAndStandards/Framework_for_assessing_early_rehab_needs_following_ICU.aspx

22 Turner-Stokes L, Corner EJ, Siegert RJ, etal. The post-ICU presentation screen (PICUPS) and rehabilitation prescription (RP) for intensive care survivors part I: development and preliminary clinimetric evaluation. J Intensive Care Soc 2021;1751143720988715. doi: 10.1177/1751143720988715.

23 Faculty of Intensive Care, ICUSteps. FICM position statement and provisional guidance: recovery and rehabilitation for patients following the pandemic. 2020. https:/www.ficm.ac.uk/sites/default/files/ficm_rehab_provisionaL_guidance.pdf.

This article is made freely available for use in accordance with BMJ's website terms and conditions for the duration of the covid-19 pandemic or until otherwise determined by BMJ. You may use, download and print the article for any lawful, non-commercial purpose (including text and data mining) provided that all copyright notices and trade marks are retained. 